\title{
RELATOS DE EXPERIENCIA

\section{Projetos de letramento e suas contribuições para a ampliação dos conhecimentos locais e globais sobre a diversidade cultural brasileira}

Andressa Regiane Gesser ${ }^{\mathrm{I}}$ II

https://dx.doi.org/10.24109/2176-6681.rbep.102i261.4286

\section{Resumo}

Este trabalho tem como objetivo apresentar e analisar um projeto de letramento voltado à ampliação do conhecimento relacionado à diversidade cultural brasileira, no que se refere a aspectos como alimentação, costumes, vestimentas, tradições, danças e estilos musicais. Tal projeto foi desenvolvido em uma escola pública situada na região do Vale do Itajaí (Santa Catarina), em parceria com o subprojeto "Letras-Português" do Programa Institucional de Bolsas de Iniciação à Docência (Pibid), da Universidade Regional de Blumenau (Furb). Visando ao desenvolvimento de práticas de letramento relacionadas ao contexto social, o trabalho foi realizado com base em um levantamento de necessidades, no qual foram utilizadas as seguintes estratégias: observações participantes, questionário com perguntas abertas e fechadas e uma proposta de produção de texto inicial. A partir dessas informações, foi realizado um projeto de letramento,

Universidade Federal de Santa Catarina (UFSC). Florianópolis, Santa Catarina, Brasil. E-mail:<andressa regianegesser@gmail. com>; <https://orcid. org/0000-0001-6365-9900>

II Mestra em Linguística pela Universidade Federal de Santa Catarina (UFSC). Florianópolis, Santa Catarina, Brasil. que foi avaliado de forma processual. As informações e as análises realizadas ao longo do processo foram registradas por meio de diário de campo reflexivo e examinadas com base na perspectiva dos (Novos) Estudos do Letramento (New Literacy Studies). A análise dos resultados das atividades realizadas apontou que essas contribuíram para a ampliação das práticas de letramento relacionadas à cultura brasileira em nível local e global.

Palavras-chave: letramentos locais e globais; Pibid; projeto de letramento. 


\begin{abstract}
Literacy projects and their contributions to the expansion of local and global knowledge of Brazilian cultural diversity
\end{abstract}

This study aims to present and analyze a literacy project geared towards the knowledge expansion of the knowledge of Brazilian cultural diversity, related to aspects such as food, customs, clothing, traditions, dances and musical styles. This project was developed in a public school located in the region of Vale do Itajaí (Santa Catarina), in partnership with the subproject "Letras-Português", which is part of the Programa Institucional de Bolsas de Iniciação à Docência (Pibid), in the Universidade Regional de Blumenau (Furb). To propel the development of literacy practices related to social context, the study was carried out from an analysis of needs, in which the following strategies were used: participant observation, questionnaire with open and closed questions, and an initial text production proposal. From this information, a literacy project was developed, which was being evaluated in a procedural way. The information and analyses carried out throughout the process were recorded through a reflective field diary and analyzed based on the perspective of the New Literacy Studies. The final analysis of performed activities showed that they contributed to the expansion of literacy practices related to Brazilian culture at a local and global level.

Keywords: global and local literacies; literacy project; Pibid.

\title{
Resumen \\ Proyectos de literacidad y sus contribuciones a la expansión de los conocimientos locales y globales sobre la diversidad cultural brasileña
}

Este trabajo tiene como objetivo presentar y analizar un proyecto de literacidad destinado a la ampliación del conocimiento relacionado con la diversidad cultural brasileña respecto a aspectos como la alimentación, costumbres, vestimentas, tradiciones, danzas y estilos musicales. Este proyecto se desarrolló as en una escuela pública ubicada en la región del Vale do Itajaí, en asociación con el subproyecto Letras-Portugués de Pibid-Programa Institucional de Becas de Iniciación a la Docenciade una universidad comunitaria. Con el objetivo de desarrollar prácticas de literacidad relacionadas con el contexto social, el trabajo se realizó a partir de una identificación de necesidades, utilizando las siguientes estrategias: Observaciones participantes, cuestionario con preguntas abiertas y cerradas y una propuesta para la producción de un texto inicial. A partir de esta información, se llevó a cabo un proyecto de literacidad, que fue evaluado progresivamente. La información y los análisis llevados a cabo durante todo el proceso se registraron por medio de un diario de campo reflexivo y se analizaron en función de la perspectiva de los (Nuevos) Estudios de la Literacidad (New Literacy Studies). El análisis de los resultados de las 
actividades realizadas mostró que éstas contribuyeron a la ampliación de las prácticas de literacidad relacionadas con la cultura brasileña a nivel local y global.

Palabras clave: literacidades locales y globales; proyecto de literacidad; Pibid.

\section{Introdução}

Durante muitos anos, a prática docente, em muitos contextos educacionais, esteve centrada no currículo, isto é, nos conteúdos segmentados a serem ensinados. Esses conteúdos eram geralmente lecionados sem nenhuma relação histórico-social com o contexto em que os estudantes estavam inseridos e, muitas vezes, esse ensino partia dos conteúdos que naturalizavam os processos de dominação, sem relacioná-los com a realidade escolar local e sem possuir caráter crítico e reflexivo. Essa forma de ensino alinhada à escola tradicional é atualmente criticada por não considerar os conhecimentos prévios dos estudantes, nem o contexto histórico-político e social no qual eles estão inseridos. Em decorrência dessas características, tais práticas educativas não promovem o desenvolvimento de cidadãos críticos (Freire, 1987, 1996; Giroux, 1990), estando em dissonância com o que sugerem os documentos parametrizadores, como os Parâmetros Curriculares Nacionais (Brasil. MEC, 1998) e a Base Nacional Comum Curricular (Brasil. MEC, 2017).

Muitos autores, visando romper com essa perspectiva tecnicista e promover um ensino que objetive a criticidade e a reflexão dos estudantes e de todos os envolvidos no contexto escolar, vêm propondo projetos de letramento baseados na perspectiva dos (Novos) Estudos do Letramento (Kleiman, 2000; 2001; 2007; 2009; 2012; Baltar, 2010; Oliveira, 2010; Rojo, 2009; Oliveira; Tinoco; Santos, 2014; Correia, 2016; Carvalho; Ribeiro, 2016; Souza, 2017; Sousa; Noronha, 2017; Brandão; Tinoco, 2017; Souza; Oliveira, 2017; Marques; Kleiman, 2019). Com base nas reflexões apresentadas por esses autores, parte-se do pressuposto de que o trabalho educativo conduzido por meio de projetos de letramento pode promover a aprendizagem significativa, crítica, reflexiva, coletiva e coerente com o contexto educacional. Kleiman (2000) conceitua projeto de letramento como:

\footnotetext{
um conjunto de atividades que se origina de um interesse real na vida dos alunos e cuja realização envolve o uso da escrita, isto é, a leitura de textos que, de fato, circulam na sociedade e a produção de textos que serão lidos, em um trabalho coletivo de alunos e professor, cada um segundo sua capacidade. O projeto de letramento é uma prática social em que a escrita é utilizada para atingir algum outro fim, que vai além da mera aprendizagem da escrita (a aprendizagem dos aspectos formais apenas), transformando objetivos circulares como 'escrever para aprender a escrever' e 'ler para aprender a ler' em ler e escrever para compreender e aprender aquilo que for relevante para o desenvolvimento e a realização do projeto. (Kleiman, 2000, p. 238).
} 
Desse modo, é possível notar que os projetos de letramento surgem de um interesse real na vida dos estudantes e, durante sua realização, envolvem práticas de leitura e de escritura num trabalho coletivo. Vale salientar que as práticas de leitura e a escrita, no bojo desse tipo de projeto, buscam utilizar textos (orais ou escritos) que de fato circulam no meio social. A produção de textos, nessa perspectiva metodológica, não é feita apenas para envolver a escrita e para ser avaliada; pelo contrário, há uma questão social sobre o que escrever e para quem escrever, sendo o texto compartilhado para que outras pessoas possam lê-lo.

Ademais, Baltar (2010) faz uma crítica à concepção reducionista presente em algumas práticas de letramento, destacando a importância de elas abrangerem tanto as práticas de letramento de prestígio globais quanto as práticas de letramentos locais. O autor destaca ainda a importância de essas práticas serem organizadas em torno de "processos de ensinoaprendizagem que assegurem aos sujeitos envolvidos a sensibilização para o reconhecimento e uso dos gêneros textuais/discursivos que movimentam, estabilizam e emergem dessas práticas" (Baltar, 2010, p. 179).

A perspectiva de práticas de letramento acima apresentada coaduna com a concepção de educação proposta por Paulo Freire (1987, 1996), autor que buscou transformar a educação por meio da pedagogia crítica, visando fazer com que os estudantes aprendessem a ler o mundo paralelamente à leitura da palavra. Assim, os sujeitos poderiam questionar os modelos sociais, políticos e ideológicos vigentes na sociedade, promovendo sua emancipação e seu empoderamento por meio da linguagem e do pensamento crítico.

Este trabalho busca apresentar e analisar um projeto de letramento voltado à ampliação do conhecimento relacionado à diversidade cultural brasileira, no que se refere a aspectos como alimentação, costumes, vestimentas, tradições, danças e estilos musicais. Tal projeto foi desenvolvido em uma escola pública em parceria com o subprojeto "LetrasPortuguês" do Programa Institucional de Bolsas de Iniciação à Docência (Pibid) da Universidade Regional de Blumenau (Furb), programa do qual participei como bolsista durante minha graduação (2013-2016).

O Pibid é um programa financiado pela Coordenação de Aperfeiçoamento de Pessoal de Nível Superior (Capes) e regido inicialmente pela Portaria $\mathrm{n}^{\circ} 72$, de 9 de abril de 2010, e pelo Decreto $\mathrm{n}^{\circ} 7.219$, de 24 de junho de 2010. O programa oferece bolsas para acadêmicos dos cursos de licenciatura (bolsistas de iniciação à docência), professores supervisores que atuam na educação básica e coordenadores de diferentes áreas da licenciatura em universidades brasileiras que aderem a ele. Como objetivos, o Pibid visa melhorar a qualidade de ensino, incentivar a formação docente de acadêmicos dos cursos de licenciatura e promover práticas de aprendizado significativas nas escolas por meio dos subprojetos. Na universidade em que este trabalho foi desenvolvido, há subprojetos do Pibid em diversas áreas do conhecimento, implementados em escolas públicas da região do Vale do Itajaí (Santa Catarina). 
Na próxima seção, será apresentado o referencial teórico que embasou este estudo, com destaque na perspectiva do letramento como prática social. Em seguida, será descrita a metodologia utilizada no planejamento. Após, serão apresentadas as atividades realizadas e os efeitos produzidos no contexto histórico, cultural e político. Por fim, serão tecidas algumas considerações acerca do trabalho realizado.

\section{Letramentos e práticas sociais}

A perspectiva dos (Novos) Estudos do Letramento pretende adicionar os aspectos socioculturais ao letramento, considerando-o não como algo homogêneo, mas como um conjunto plural de práticas sociais. Diante dessa visão de práticas sociais na pluralidade, o termo "letramento" tornou-se "letramentos", no plural (Gee, 1994).

Os estudos do letramento surgiram para dar conta da infinidade de práticas que envolvem a leitura e a escrita, sendo essas caracterizadas como ferramentas para agir socialmente (Kleiman, 2009) - consideram aspectos que envolvem as relações de poder, as mais diversas formas de opressão, nas quais a língua escrita pode operar como um instrumento, os saberes impostos por uma determinada comunidade ou grupo social e também promovem, com base em Paulo Freire (1987), a leitura do mundo para criticá-lo e transformá-lo.

Nas últimas décadas, muitos pesquisadores adentraram no campo dos (Novos) Estudos do Letramento a fim de compreenderem o letramento, seus eventos e suas práticas. Barton e Hamilton (1998) veem o letramento como um conjunto de práticas sociais, mediadas por eventos com textos escritos, em diferentes situações da vida, sendo esse letramento sempre situado historicamente. Os autores afirmam que as práticas de letramento estão modeladas pelas instituições sociais e pelas relações de poder, fazendo com que algumas sejam consideradas mais dominantes ou influentes do que outras. Afirmam ainda que tais práticas possuem um propósito e estão inseridas em objetivos sociais e práticas culturais mais amplas e, por isso, podem mudar por meio de processos informais de aprendizagem e construção de sentido.

De acordo com Barton e Hamilton (1998), é nas práticas sociais que o letramento cumpre sua função social. Assim, a teoria social do letramento está constituída por práticas letradas, que são formas culturais generalizadas de uso da língua escrita, em que se encontra alguma inspiração para a vida. São os processos sociais que conectam as pessoas entre si, incluindo seus conhecimentos compartilhados, representados em ideologias e identidades sociais (Barton; Hamilton, 1998).

Nos (Novos) Estudos do Letramento, muitos autores destacam a importância dos eventos e das práticas de letramento (Barton; Hamilton, 1998; Heath, 1982; Street, 2000; Hamilton, 2000, entre outros). Os eventos de letramento podem ser compreendidos como "[...] ocasiões em que a linguagem escrita é parte integrante da natureza das interações dos participantes e seus processos e estratégias interpretativas" (Heath, 
1982, p. 50, tradução nossa). Barton e Hamilton (1998) consideram que tais eventos são atividades contextualizadas em que a escrita possui um papel. Além disso, são episódios observáveis que surgem e se formam nas práticas sociais.

Street (2000) considera o conceito de evento de letramento útil, pois, com base nele, os pesquisadores podem focar uma situação particular, em que há eventos acontecendo e que são possíveis de serem observados. No entanto, não há evidência, segundo Street (2000), de como os conceitos e as reflexões são construídos dentro de um evento de letramento, por isso o autor sugere o conceito de práticas de letramento. Esse conceito tenta lidar com os padrões de atividade que subjazem à participação em eventos, a fim de relacioná-los a algo mais amplo, cultural e social referente às formas particulares de se pensar e de se fazer a leitura e a escrita dentro de um contexto (Street, 2000).

Hamilton (2000), ao diferenciar eventos de práticas de letramento, utilizou a metáfora do iceberg. Para a autora, os eventos de letramento são a ponta do iceberg, pois são visíveis. Já as práticas de letramento constituem toda a parte que fica abaixo do topo do iceberg, a base, ou seja, são invisíveis, pois envolvem recursos como conhecimento, sentimentos, propósitos e valores sociais. Segundo a autora, as práticas de letramento podem ser somente inferidas com base em evidências observáveis no contexto.

Os conceitos de evento e práticas de letramento são apresentados por vários autores, pois fazem parte, de fato, do processo de letramentos em que os indivíduos participam durante sua vida. Diante disso, Kalman (2003) afirma que para o indivíduo ser letrado ele tem que utilizar a língua escrita para participar do mundo social. Em razão disso, a autora destaca a importância das condições materiais para a prática de leitura e escritura, em termos de acesso e disponibilidade. Para a autora,

\footnotetext{
a disponibilidade indica a presença física de materiais impressos, a infraestrutura para distribuição (biblioteca, pontos de venda de livros, revistas, jornais, serviços de correio, etc.), enquanto o acesso se refere às oportunidades tanto para participar em eventos de língua escrita (situações em que o sujeito fica na frente de outros leitores e escritores) como em aprender a ler e escrever. (Kalman, 2003, p. 39, grifo do autor, tradução nossa).
}

Os letramentos estão presentes no cotidiano social dos indivíduos por meio dos eventos de letramento. No entanto, nem todos os indivíduos têm acesso a determinados eventos. Tal situação evidencia uma questão muito maior relacionada à desigualdade social (Rojo, 2009).

Nesta seção, foi abordado o conceito de prática social e a sua associação ao termo letramento, bem como o fato de as práticas de leitura e a escrita serem situadas histórica e socialmente. Também foi apresentada a diferenciação dos termos "eventos" e "práticas de letramento", assim como foi ressaltada a importância do acesso e da disponibilidade dessas práticas para que os indivíduos se desenvolvam no processo de letramento. Na próxima seção, propõe-se um olhar reflexivo sobre o ensino de Língua Portuguesa envolvendo o letramento e as práticas sociais por meio de projetos. 


\section{O ensino de língua por meio de projetos de letramento}

Como já destacado na introdução deste trabalho, o desenvolvimento de projetos de letramento tem uma função muito importante no ensino da língua, principalmente quando promove uma visão crítica acerca da realidade presente no cotidiano, no contexto local, para assim questionar a realidade mais ampla e transformá-la. Tal aspecto significa promover o processo de empoderamento dos estudantes - que tem a finalidade, de acordo com McLaren (1988), de contribuir para que os estudantes desenvolvam uma capacidade de análise crítica da realidade na direção de transformar a ordem social dominante.

Marques e Kleiman (2019) destacam que a aprendizagem das práticas de linguagem por meio de projetos de letramentos tem mais chances de ser exitosa no sentido de promover uma maior conscientização sobre o que é agir socialmente. Dessa forma, essas práticas favorecem a agência cívica e a participação social.

Em relação às características dos letramentos, Oliveira (2010) destaca que esses são múltiplos, dêiticos, ideológicos, culturais e críticos. Múltiplos, pois seus estudos englobam toda a complexidade da vida social, a grande pluralidade de contextos sociais e culturais, a força das mudanças sociais e as suas implicações nas práticas de letramento, como as diferentes formas de textos midiáticos e expressões semióticas. Os letramentos são dêiticos, pois as práticas de leitura e escritura mudam em termos de forma e função; evoluem e se transformam segundo condições socio-históricas. São ideológicos, pois cada grupo social busca assegurar seus interesses, suas crenças, seus valores, isto é, sua ideologia. Culturais, pois estão presentes em contextos culturais diferentes, sendo tanto locais quanto globais. Por fim, os letramentos são críticos, pois é por meio de suas práticas que o cidadão pode se mostrar crítico e capaz de analisar e desafiar as forças opressoras da sociedade (Oliveira, 2010).

Diante dessas características, o ensino precisa, de acordo com Rojo (2009), possibilitar aos estudantes a participação em várias práticas sociais que utilizam os letramentos de maneira ética, crítica e democrática. Além disso, é preciso que a educação linguística leve em consideração os letramentos múltiplos, abrangendo as culturas locais e globais e os letramentos críticos, para assim desvendar os sentidos, as intenções e os significados presentes em um texto com um olhar crítico. Por fim, o ensino deve acolher também os letramentos multissemióticos, ou seja, a multiplicidade das práticas discursivas com as diversas semioses (Rojo, 2009).

Ao elencar esses pontos em um projeto de letramento, acredita-se que "a escola pode formar um cidadão flexível, democrático e protagonista, que seja multicultural em sua cultura e poliglota em sua língua" (Rojo, 2009, p. 115). O argumento da autora indica que é por meio desses projetos que os estudantes podem ter acesso aos eventos de letramento presentes no contexto escolar. Ao serem inseridos nas práticas de letramento de maneira a pensar criticamente toda questão cultural e social enraizada nos discursos presentes nessas práticas, poderão se tornar protagonistas na busca pela transformação. 
Com base nessas discussões sobre o ensino por meio de projetos de letramento, as quais englobam os aspectos críticos, sociais, culturais e semióticos da língua, propõe-se, na próxima seção, relatar e analisar um projeto de letramento, desenvolvido em uma escola municipal em parceria com o subprojeto "Letras-Português" do Pibid.

\section{Percurso metodológico: processo de construção do projeto de letramento}

Todo o projeto de letramento apresentado foi desenvolvido com base na perspectiva dos (Novos) Estudos do Letramento, previamente caracterizada, e foi realizado coletivamente pelas bolsistas, pela coordenadora e pela supervisora do subprojeto "Letras-Português" do Pibid da Universidade Regional de Blumenau do Vale do Itajaí em uma escola pública municipal situada na mesma região. O objetivo central do subprojeto foi a criação de projetos de letramento interdisciplinares, valorizando os multiletramentos, conforme propõem Rojo e Moura (2012), e práticas pedagógicas significativas dentro do contexto da comunidade escolar. Multiletramentos, na visão de Rojo e Moura (2012, p. 13), é um termo que abrange "a multiculturalidade característica das sociedades globalizadas e a multimodalidade dos textos por meio dos quais a multiculturalidade se comunica e informa".

$\mathrm{O}$ trabalho foi realizado com base em um levantamento voltado à caracterização do contexto escolar, dos estudantes e de suas necessidades. Nessa etapa, foram utilizadas as seguintes estratégias: i) observações participantes com o intuito de compreender o contexto escolar, conhecer a professora supervisora, os estudantes e o entorno da escola; ii) diário de campo, no qual foram descritas todas as etapas do projeto, desde a inserção na comunidade escolar até a finalização das atividades realizadas; iii) questionário com perguntas abertas e fechadas, visando conhecer os eventos de letramento, o acesso e a disponibilidade de recursos tecnológicos e de livros, em consonância com a perspectiva de Kalman (2003), bem como os assuntos de interesse dos estudantes nas aulas de Língua Portuguesa; e iv) uma proposta de produção de texto inicial, visando identificar o conhecimento linguístico e cultural prévio dos estudantes. A partir dessas informações, foi realizado um projeto de letramento, construído coletivamente e aberto a modificações de acordo com a avaliação processual da equipe e das anotações do diário de campo reflexivo. O detalhamento das atividades realizadas no projeto de letramento e a discussão dos resultados serão objeto da próxima seção.

\section{Resultados e discussão: projeto "Que Brasil é esse?"}

Com base nas observações realizadas nas aulas de Língua Portuguesa da turma do $8^{\circ}$ ano, bem como por meio da aplicação do questionário, foi possível identificar a existência de uma diversidade cultural na turma, o que provavelmente é decorrente de os estudantes serem provenientes 
de diversas regiões do País. Os resultados obtidos nessa etapa também indicaram temas de interesse dos alunos no que se refere à Língua Portuguesa e suas intersecções, conforme descrito no diário de campo:

Com base na análise dos questionários, percebi que a maioria dos estudantes gostam de ler desde gibis até romances, embora não tenham identificação com alguns aspectos da língua portuguesa, tais como o conteúdo gramatical. No entanto, tanto os questionários, como também as observações participantes, mostraram que eles gostariam de aprender 'teatro', 'poemas', 'textos de opinião', 'música', entre outros temas relacionados à cultura. A maioria possui parentes em outros estados, como Paraná, São Paulo e Bahia e pode-se perceber relações entre suas preferências culturais e a região do Brasil da qual eles são provenientes. (Diário de campo reflexivo).

Segundo essas observações e o instrumento utilizado para analisar os eventos de letramento aos quais os estudantes estão expostos, foi possível notar a importância de tentar compreender o contexto escolar. A análise deste "[...] proporciona oportunidades para inserir o trabalho escolar em uma atividade significativa, própria desse âmbito, permitindo mostrar, assim, a relação imbricada entre texto, contexto e prática letrada [...]" (Kleiman, 2000, p. 241).

Com base na constatação e por meio das observações da existência de uma grande diversidade cultural na sala de aula, optou-se por proporcionar aos estudantes a chance de escreverem sobre sua realidade local/global em uma proposta de produção inicial de um texto dissertativo sobre o tema "Que Brasil é esse?", nome dado ao projeto posteriormente. Essa produção permitiu um olhar reflexivo sobre os conhecimentos culturais dos estudantes e sobre os aspectos textuais de suas produções.

Ao analisar as produções iniciais dos estudantes, foram constatadas dificuldades na elaboração de um texto dissertativo, como a escrita do texto em tópicos e textos muito genéricos, sem aprofundamento das ideias, ou abordando somente o descobrimento do Brasil. Outros textos, no entanto, abordavam a cultura brasileira, geralmente exposta na mídia por meio do futebol e do carnaval e, em relação à culinária, traziam apenas exemplos como o arroz e o feijão. Alguns textos questionavam a realidade do País e davam dicas para se tornar um lugar melhor. Contudo, essas ideias não correspondiam à tipologia textual. Os estudantes também mostraram grandes dificuldades em relação à coesão e à coerência e apresentaram muitos erros ortográficos.

Diante das dificuldades encontradas nos textos, foi realizada uma exposição dialogada interdisciplinar sobre alguns aspectos culturais do Brasil. Essa discussão teve como ponto de partida a chegada dos diversos povos ao País e o que eles trouxeram para a cultura brasileira. Foram abordadas também as formas de opressão que alguns desses povos, vindos de outros países, sofreram por terem sido submetidos à escravidão, assim como dos povos já existentes no Brasil, a exemplo da população indígena, que teve que se submeter às ordens de quem, baseado no discurso eurocêntrico, tinha poder. 
Segundo essa exposição dialogada, foram elencadas as heranças culturais que todos os povos deixaram no Brasil e como isso se manifesta na cultura brasileira atualmente. Os estudantes participaram trazendo seus conhecimentos culturais prévios e aqueles provenientes de outras regiões do País e relataram as especificidades culturais de onde vieram. Após essa exposição dialogada, foi possível fazer uma associação das práticas de letramento globais e locais e suas relações com determinados povos, como relatado no diário de campo:

Essa discussão sobre aspectos culturais aparentou ser interessante para os estudantes. Aqueles que eram mais tímidos e não participavam muito nas aulas, tiveram a oportunidade de relatar sobre algumas festas e comidas típicas dos lugares de onde eram provenientes. Percebi que a turma estava motivada a participar e a ouvir o que cada estudante tinha a dizer. (Diário de campo reflexivo).

Por meio dessa prática inicial, o professor pôde assumir o papel de agente do letramento (Kleiman, 2006), possibilitando que os estudantes participassem desse evento trazendo suas vozes e experiências, com base em uma perspectiva horizontal de ensino. Sobre isso, Oliveira, Tinoco e Santos (2014, p. 55) afirmam:

Esse novo modo de gerar conhecimento, além de descentralizar a ação e redimensionar a função do professor e do aluno, salienta habilidades, saberes e competências de todos os agentes envolvidos na ação de ensinar e aprender, geralmente apagadas pelo monopólio da docência, legitimado institucionalmente.

Após essa discussão sobre os aspectos culturais das diferentes regiões dos estudantes, foi apresentada à turma a ideia de trabalhar a cultura brasileira no projeto. O problema social, considerado o ponto de partida, foi a ampliação dos conhecimentos culturais brasileiros. Para isso, os estudantes foram divididos em cinco grupos, correspondendo às cinco regiões brasileiras, a fim de envolvê-los em práticas de letramento interdisciplinares e interculturais com vistas aos multiletramentos, como propõem Rojo e Moura (2012, p. 8):

Trabalhar com multiletramentos pode ou não envolver (normalmente envolverá) o uso de novas tecnologias de comunicação e de informação ('novos letramentos'), mas caracteriza-se como um trabalho que parte das culturas de referência do alunado (popular, local, de massa) e de gêneros, mídias e linguagens por eles conhecidos, para buscar um enfoque crítico, pluralista, ético e democrático - que envolva agência de textos/discursos que ampliem o repertório cultural, na direção de outros letramentos [...].

Interdisciplinaridade, neste projeto, consistiu na utilização de conhecimentos vindos de diversas disciplinas, como História, Geografia e Artes. Sobre o termo, Severo e Paula (2010, p. 28) afirmam que a interdisciplinaridade "supõe um diálogo e uma troca de conhecimentos, de análises, de métodos entre duas ou mais disciplinas".

O projeto de letramento teve como objetivos iniciais: i) ampliar o conhecimento cultural a respeito da diversidade presente no Brasil; 
ii) promover situações voltadas à ampliação dos conhecimentos gramaticais e estilísticos dentro do contexto da diversidade cultural; iii) oportunizar a ampliação dos mecanismos linguístico-discursivos; e iv) aperfeiçoar o repertório de práticas discursivas. O produto final do projeto foi a encenação sobre os aspectos culturais do Brasil, abordando os ritmos, as vestimentas, a culinária e os costumes de cada região, fazendo com que os estudantes pudessem refletir sobre bens culturais ligados à pluralidade de culturas e línguas de dentro e fora da comunidade em que estão inseridos.

Os estudantes tinham quatro aulas de Língua Portuguesa durante a semana, sendo duas com as bolsistas do Pibid e duas com a professora supervisora, mas todas as aulas foram planejadas conjuntamente e realizadas de forma integrada. Isso se relaciona com o que Kleiman (2009, p. 9) destaca acerca dos projetos de letramento:

[...] a articulação do trabalho escolar em torno de projetos de letramento confere organicidade e unidade ao conjunto de atividades a serem realizadas durante o ano escolar, facilitando o trabalho colaborativo e em equipe do pessoal da escola. Com o projeto, é possível trabalhar letramentos, rever a relação entre educadores, crianças e comunidade; organizar o tempo e o espaço escolar, de modo a garantir que a construção de saberes sobre a escrita, que servirão a essas crianças ao longo de suas vidas, ocupe lugar central nas atividades curriculares e seja meta de todos os que trabalham na escola.

Os temas abordados no projeto de letramento foram: i) variações linguísticas no País e preconceito linguístico; ii) heranças históricas: culinária, costumes, festas e roupas de cada região do Brasil; iii) ritmos musicais presentes no País; iv) elaboração de música e videoclipe; v) roupas típicas de cada região; vi) diversidade da culinária brasileira; vii) heranças culturais das diferentes regiões do Brasil; e viii) diferenças culturais: a celebração da diversidade.

Durante todo o processo de implementação do projeto, procurou-se trazer um pouco da cultura do Brasil, por meio de recursos audiovisuais, textos e exposições dialogadas em que os estudantes pudessem ter espaço para mostrar seus conhecimentos e suas vivências sobre a cultura. Nesse sentido, foi possível contribuir para que eles se tornassem autores reflexivos sobre os acontecimentos de suas vidas, conforme propõe Geraldi (2015, p. 100):

[...] a herança cultural exige que cada sujeito - professor e alunos - se torne autor: refletindo sobre o seu vivido, escrevendo seus textos e estabelecendo novas relações com o já produzido. Isto exige repensar o ensino como projeto, e para dar conta de um projeto não se pode esporadicamente conceder lugar ao acontecimento. O projeto como um todo tem de estar sempre voltado para as questões do vivido, dos acontecimentos da vida, para sobre eles construir compreensões, caminho necessário da expansão da própria vida.

Por meio das práticas e dos eventos de letramento presentes no projeto, os estudantes puderam aperfeiçoar seus conhecimentos sobre a cultura de nosso País. Na aula sobre variação linguística, por exemplo, foram 
apresentadas notícias e reportagens de jornais de diversas regiões do Brasil. Por meio desses eventos de letramento, os estudantes puderam perceber os fatores causadores dessa variação, como idade, região geográfica, classe social e sexo (Bagno, 2007), e compreender que tais variações linguísticas são típicas da nossa cultura e devem ser respeitadas. Na aula sobre as heranças culturais, foram apresentadas, por meio de vídeos e imagens, manifestações culturais presentes em cada região do País e foi pedido que os estudantes relatassem suas experiências e memórias a elas relacionadas. Alguns participantes falaram de como é o carnaval na região Nordeste e compararam com a cultura local, onde não é tão comum comemorar esse feriado. Outros estudantes, por exemplo, também relataram aspectos culturais de uma festa típica alemã que acontece anualmente na região em que a escola está situada. Essas atividades estão em consonância com o que propõe Rojo (2009), ao ressaltar a importância do diálogo multicultural. A autora afirma que:

Cabe também à escola potencializar o diálogo multicultural, trazendo para dentro de seus muros não somente a cultura valorizada, dominante, canônica, mas também as culturas locais e populares e a cultura de massa para torná-las vozes de um diálogo, objetos de estudo e de crítica. (Rojo, 2009, p. 12).

Na aula seguinte, foram apresentados diversos gêneros musicais por meio de músicas, e os estudantes foram solicitados, em pequenos grupos, a identificar o gênero e o cantor. Essa atividade teve uma participação ativa e, por meio dela, foi possível verificar que eles tinham uma maior identificação com os estilos musicais de rap e funk. Após apresentar os ritmos musicais presentes no Brasil, foram trazidas duas músicas mais antigas de MPB ("Valsinha", de Chico Buarque, e "Sonho de uma Flauta", do Teatro Mágico) para que os estudantes acompanhassem na letra as rimas exibidas nessas canções. Essa prática trouxe um estranhamento por parte deles, pois alguns nunca tinham tido acesso a essas músicas e em razão da temática ser bem diferente das músicas que eles escutam.

Foi proposta, então, a atividade de elaboração de uma música dentro de qualquer ritmo, trazendo críticas sobre o Brasil. Nessa atividade, os estudantes tiveram preferência pelos gêneros musicais rap e pop. A próxima etapa do projeto foi a elaboração de um videoclipe dessas músicas para ser apresentado à comunidade escolar. Este teve como objetivo envolver os estudantes no trabalho com os letramentos semióticos (Rojo, 2009) e com as tecnologias digitais. Nessa etapa, alguns grupos demonstraram interesse de alterar a letra de suas músicas para outra temática. Essa sugestão foi aceita pelas bolsistas e pela professora supervisora, pois, assim, os estudantes poderiam mostrar um pouco de seu universo cultural, mesmo que isso significasse mudanças no planejamento do projeto de letramento. Essa ação de adequação está em consonância com o que propõe Oliveira (2008), ao destacar que tais projetos não precisam ser utilizados como uma receita do fazer pedagógico. Nessa direção, a autora evidencia que "[...] o trabalho com projetos apresenta-se como um apelo à experiência que tem 
como ponto de partida a incerteza, o recurso à criatividade, delineando-se e criando corpo à medida que se coloca em ação" (Oliveira, 2008, p. 97). A perspectiva de Oliveira coaduna com a noção de planejamento flexível de Geraldi (2015). Segundo o autor:

[...] focalizado na aprendizagem, o ensino não pode ter um planejamento inflexível. Importa muito mais aprender a aprender do que aprender o já sabido e definido. O conhecimento sistematizado deve fazer parte do percurso e não deve ser o fim do percurso (Geradi, 2015, p. 100).

Esses videoclipes foram apresentados para a turma e, à medida que eram exibidos, os colegas faziam sugestões do que poderia ser aprimorado, para posterior apresentação à comunidade escolar. O próximo assunto foi relacionado às roupas típicas de cada região. Tal tema foi abordado por meio de vídeos de apresentações de danças presentes em diferentes regiões do Brasil e, em seguida, foi feita uma discussão sobre as danças e as roupas típicas. Durante essa discussão, foram elencadas algumas características dos figurinos no quadro e foi proposto que cada grupo elaborasse o traje referente à região de seu grupo, em forma de cartaz.

O próximo tema trabalhado foi sobre a culinária brasileira, por meio da apresentação de alguns dos pratos típicos de cada região, mediante um fôlder elaborado pelas bolsistas. Após apresentação e discussão dos pratos típicos, foi proposto que cada grupo pesquisasse e demonstrasse para a turma um dos pratos da região de seu grupo, conforme o seguinte relato:

Os grupos se engajaram efetivamente nessa proposta, além de produzirem um texto informativo com os principais pratos típicos de cada região, trouxeram para aula pratos como bolo de chocolate, tapioca, bolo de fubá e pão de queijo. (Diário de campo reflexivo).

Com base no diário reflexivo, percebe-se que, por meio dos projetos de letramento, os estudantes vivenciam o conhecimento. Isso está em consonância com o que propõem Marques e Kleiman (2019, p. 22), ao afirmarem que "a aprendizagem se dá vivencialmente, isto é, o modo situado: o que os alunos aprendem tem um relevante papel no conhecimento que querem construir.".

A próxima etapa do projeto consistiu na produção coletiva de um texto dissertativo com base nos conhecimentos desenvolvidos nas aulas. Para a elaboração desse texto, foram retomados alguns aspectos do texto dissertativo, como a introdução, o desenvolvimento e o fechamento com a conclusão. Esse texto foi escrito com o propósito de elencar os conhecimentos culturais de cada região estudada e de ser apresentado para a comunidade escolar, em uma noite cultural, como parte do produto final do projeto.

A última aula do projeto "Que Brasil é esse?" consistiu no ensaio e na organização do produto final, que se constituiu em uma encenação, para a noite cultural, de aspectos culturais do Brasil, envolvendo bens culturais relacionados à multiculturalidade (Rojo, 2009), presentes tanto no contexto local quanto global. Nessa noite, ocorreu a socialização dos trabalhos dos estudantes, contando com a presença de pais e responsáveis, dos professores e da direção da escola. Essa socialização foi desenvolvida 
por meio da leitura do texto dissertativo de cada região por um estudante de cada grupo e pela apresentação presencial de trajes típicos. As demais heranças culturais eram expostas à comunidade escolar pelas fotos dos trabalhos exibidas no telão, simultaneamente com a leitura do texto.

Ao final do projeto, percebeu-se que os objetivos foram alcançados e que os estudantes apresentaram uma visão de cultura mais crítica, que vai além do que é exposto pela mídia. Em relação aos usos sociais da escrita, o projeto cumpriu com o seu objetivo de "repensar o ensino da escrita a fim de que esta passe a fazer parte do mundo social do aluno" (Kleiman, 2012 , p. 30), visto que os estudantes produziram textos orais e escritos que circularam pela escola.

\section{Considerações finais}

O projeto de letramento relatado teve como objetivo promover a ampliação do conhecimento relacionado à diversidade cultural brasileira no que se refere a aspectos como alimentação, costumes, vestimentas, tradições, danças e estilos musicais com base na perspectiva dos (Novos) Estudos do Letramento e com um enfoque na multiculturalidade. Os resultados do trabalho mostraram que esse objetivo foi atingido, uma vez que os estudantes puderam ampliar o conhecimento acerca das diferentes culturas presentes em cada região do Brasil de forma crítica e reflexiva.

A perspectiva adotada, pautada no planejamento de todas as atividades de forma dialógica, horizontal e com base no contexto histórico-cultural dos estudantes, foi muito importante para a promoção do engajamento nas atividades e para que eles pudessem ampliar suas aprendizagens do nível local para o global, conforme apontam os ensinamentos do Paulo Freire (1996). Além disso, também possibilitou que os estudantes conseguissem ampliar a capacidade de estranhamento do processo de naturalização de algumas expressões da cultura tidas como as únicas legítimas do ponto de vista dos discursos dominantes.

Destaca-se também que este trabalho desenvolvido em uma escola pública situada na região do Vale do Itajaí, em parceria com o subprojeto "Letras-Português" do Pibid da Furb, teve contribuições que vão além dos ganhos obtidos pelos estudantes. A experiência relatada colaborou para a formação em serviço dos docentes que já estão atuando na escola, uma vez que foi construída em parceria com eles, assim como para a formação inicial de novos professores do curso de Letras que dela participaram. Dessa forma, destaca-se a relevância de programas de formação como o Pibid para a qualificação da educação pública e de qualidade no Brasil, uma vez que por meio desses programas é possível ampliar o diálogo entre a universidade e a escola, entre a teoria e a prática. Para finalizar, o Pibid, por envolver os acadêmicos de licenciatura e os professores supervisores em eventos de letramento tanto na esfera escolar como na esfera acadêmica, por meio do compartilhamento das experiências em eventos e publicação de artigos científicos, possibilita a ampliação dos conhecimentos relacionados ao campo dos processos de letramentos entre os envolvidos. 


\section{Referências}

BAGNO, M. Nada na língua é por acaso: por uma pedagogia da variação linguística. São Paulo: Parábola, 2007.

BALTAR, M. Letramentos e gêneros textuais midiático-escolares. Letras, Santa Maria, v. 20, n. 40, p. 177-190, jan./jun. 2010.

BARTON, D.; HAMILTON, M. Local Literacies: reading and writing in one community. Issues in Applied Linguistics, [S.l.], v. 10, n. 1, p. 87-92, July 1998.

BRANDÃO, L. C. L.; TINOCO, G. M. A. M. O lugar dos gêneros discursivos em projetos de letramento. Caminhos em Linguística Aplicada, Taubaté, v. 1, p. 178-198, $1^{\circ}$ sem. 2017.

BRASIL. Decreto no 7.219, de 24 de junho de 2010. Dispõe sobre o Programa Institucional de Bolsa de Iniciação à Docência - PIBID e dá outras providências. Diário Oficial da União, Brasília, DF, 25 jun. 2010. Seção 1, p. 4-5.

BRASIL. Ministério da Educação (MEC). Parâmetros Curriculares Nacionais: terceiro e quarto ciclos do ensino fundamental: língua portuguesa. Brasília, DF: MEC, 1998.

BRASIL. Ministério da Educação (MEC). Base Nacional Comum Curricular. Brasília, DF: MEC, 2017. Disponível em: <http://portal.mec. gov.br/index.php?option $=$ com_docman\&view $=$ download\&alias $=79601$ anexo-texto-bncc-reexportado-pdf-2\&category_slug=dezembro-2017pdf\&Itemid=30192 > . Acesso em: 19 mar. 2020.

BRASIL. Coordenação de Aperfeiçoamento de Pessoal de Nível Superior (Capes). Portaria $\mathrm{n}^{\circ}$ 72, de 9 de abril de 2010. Dá nova redação a Portaria que dispõe sobre o Programa Institucional de Bolsa de Iniciação à Docência - PIBID, no âmbito da CAPES. Diário Oficial da União, Brasília, DF, 12 abr. 2010. Seção 1, p. 26-27. Disponível em: <https:// www.capes.gov.br/images/stories/download/legislacao/Portaria72_ Pibid_090410.pdf >. Acesso em 23 mar. 2020.

BRASIL. Coordenação de Aperfeiçoamento de Pessoal de Nível Superior (Capes). Programa Institucional de Bolsa de Iniciação à Docência. Brasília, 2014. Disponível em: <http://www.capes.gov.br/educacaobasica/capesPIBID>. Acesso em: 23 mar. 2020.

CARVALHO, K. C. H. P.; RIBEIRO, S. C. R. Projeto de letramento: uma experiência de pesquisa no contexto PROFLETRAS. Estudos Linguísticos, São Paulo, v. 45, n. 3, p. 1120-1132, 2016. 
CORREIA, K. Projetos de letramento no ensino médio: novas perspectivas e desafios. Educação e Realidade, Porto Alegre, v. 41, n. 1, p. 259-277, jan./mar. 2016.

FREIRE, P. A importância do ato de ler: em três artigos que se completam. São Paulo: Cortez, 1987.

FREIRE, P. Pedagogia da autonomia: saberes necessários à prática educativa. São Paulo: Paz e Terra, 1996.

GEE, J. P. Background to the 'New Literacy Studies'. In: GEE, J. P. Social linguistics and literacies: ideology in discourses. Londres: Taylor \& Francis, 1994. p. 49-70.

GERALDI, J. W. A aula como um acontecimento. São Carlos: Pedro \& Editores, 2015.

GIROUX, H. Introdução. In: FREIRE, P.; MACEDO, D. Alfabetização: leitura do mundo, leitura da palavra. Rio de Janeiro: Paz e Terra, 1990. p. 1-27.

HAMILTON, M. Expanding the new literacy studies: using photographs to explore literacy as social practice. In: BARTON, D.; HAMILTON, M.; IVANIC, R. (Org.). Situated literacies. London: Routledge, 2000. p. 16-35.

HEATH, S. B. What no bedtime story means: narrative skills at home and school. Language in Society, [S.l.], v. 11, p. 49-76, 1982.

KALMAN, J. El acesso a la cultura escrita: la participación social y lla apropiación de conocimientos em eventos cotidianos de lectura y escritura. Revista Mexicana de Investigación Educativa, Ciudad de México, v. 9, n. 17, p. 37-66, enero/abr. 2003.

KLEIMAN, A. B. O processo de aculturação pela escrita: ensino da forma ou aprendizagem da função? In: KLEIMAN, A.; SIGNORINI, I. (Org.). $O$ ensino e a formação do professor: alfabetização de jovens e adultos. Porto Alegre: Artes Médicas, 2000. p. 223-243.

KLEIMAN, A. B. Os usos sociais da escrita e a educação inclusiva no Brasil. In: SEMINÁRIO INTERNACIONAL SOCIEDADE INCLUSIVA, 2., 2001, Belo Horizonte. Anais... Belo Horizonte: PUC Minas, 2001. p. 84101. Disponível em: <http://www.proex.pucminas.br/sociedadeinclusiva/ sem2/palestras.pdf $>$. Acesso em: 23 mar. 2020.

KLEIMAN, A. B. Processos identitários na formação profissional: o professor como agente de letramento. In: CORREA, M. L. G.; BOCH, F. (Org.). Ensino de língua: representação e letramento. Campinas: Mercado de Letras, 2006. p. 75-91. 
KLEIMAN, A. B. Letramento e suas implicações para o ensino de língua materna. Signo, Santa Cruz do Sul, v. 32 n 53, p. 1-25, dez. 2007.

KLEIMAN, A. B. Projetos de Letramento na Educação Infantil. Revista Caminhos em Linguística Aplicada, Taubaté, v. 1, n. 1, p. 1-10, 2009.

KLEIMAN, A. B. EJA e o ensino da língua materna: relevância dos projetos de letramento. EJA em Debate, Florianópolis, v. 1, n. 1, p. 23-38, nov. 2012.

MARQUES, I. B. A. S.; KLEIMAN, A. B. Projetos, oficinas e práticas de letramento: leitura e ação social. Revista ComSertões, [S.l.], v. 7, n. 1, p. 16-34, nov. 2019.

MCLAREN, P. L. Culture or canon? critical pedagogy and the political of literacy. Havard Educational Review, v. 58, n. 2, p. 213-234, 1988.

OLIVEIRA, M. S. Projetos: uma prática de letramento no cotidiano do professor de língua materna. In: OLIVEIRA, M. S.; KLEIMAN, A. (Org.) Letramentos múltiplos: agentes, práticas, representações. Natal: EDUFRN, 2008. p. 93-118.

OLIVEIRA, M. S. Gêneros textuais e letramento. Revista Brasileira de Linguística Aplicada, Belo Horizonte, v. 10, n. 2, p. 325-345, fev. 2010.

OLIVEIRA, M. S.; TINOCO, G. A.; SANTOS, I. B. A. Projetos de letramento e formação de professores de língua materna. Natal: EDUFRN, 2014.

ROJO, R. Letramentos múltiplos: escola e inclusão social. São Paulo: Parábola, 2009.

ROJO. R; MOURA, E. Multiletramentos na escola. São Paulo: Parábola, 2012.

SEVERO, C. G; PAULA, A. C. No mundo da linguagem: ensaios sobre identidade, alteridade, ética, política e interdisciplinaridade. São Carlos, SP: Pedro e João Editores, 2010.

SOUSA, A. C. G.; NORONHA, C. A. Curso de extensão: letramento em práticas interdisciplinares de ensino. Revista Extensão \& Sociedade, Natal, v. 7, n. 1, p. 67-83, ago. 2017.

SOUZA, A. G.; OLIVEIRA, M. S. Os projetos de letramento como instrumentos de ressignificação do tempo, do espaço e dos materiais escolares. Revista do GELNE, Natal, v. 19, p. 139-154, dez. 2017.

SOUZA, F. E. B. O ensino de língua portuguesa e os projetos de letramento: uma proposta de atividades com foco na questão alimentar 
a partir do gênero anúncio de campanha comunitária. 2017. $77 \mathrm{f}$.

Dissertação (Mestrado Profissional em Linguística) - Universidade

Federal da Paraíba, João Pessoa, 2017.

STREET, B. V. Literacy events and literacy practices: theory and practice in the New Literacy Studies. In: JONES, M. M.; JONES, K. Multilingual

literacies: reading and writing different worlds. Amsterdam: John

Benjamins, 2000.

Recebido em 25 de março de 2020.

Aprovado em 19 de abril de 2021. 